\title{
LITERATURA E VIDA PÚBLICA: EÇA E MÁRIO de CARVALHO
}

http:/ / dx.doi.org/10.11606/issn.2237-1184.v0i29p227-240

\author{
Rosa Maria Sequeira \\ CEMRI - Universidade Aberta \\ Maria Cecília Vieira \\ CEMRI - Universidade Aberta
}

\section{RESUMO}

Este artigo analisa a relação entre a literatura e a vida pública em Portugal em dois autores representativos da literatura portuguesa, Eça de Queirós e Mário de Carvalho. Eça de Queirós é provavelmente o escritor português do século XIX com mais projeção internacional. Mário de Carvalho possui atualmente uma vasta obra de mais de trinta anos que tem merecido a atribuição de vários prémios literários, nacionais e estrangeiros e é um leitor entusiástico de Eça que frequentemente menciona. Têm em comum a intenção formadora e reformadora através de uma ironia impiedosa e crítica acutilante das respetivas sociedades. Este artigo analisa algumas vertentes e instituições da sociedade portuguesa que merecem a sua crítica, nomeadamente o jornalismo, a política, as igrejas e a cultura dominante. A responsabilidade de trazer os cidadãos da apatia em que estão quanto à cultura e à política é evidente nestes dois autores que não apenas dão um testemunho da sociedade portuguesa, mas transmitem a indignação moral contra todas as formas de submissão aos poderes instituídos.

\section{ABSTRACT}

Our study aims to present the relation between literature and public life by two outstanding writers of Portuguese literature, Eça de Queirós and Mário de Carvalho. Eça de Queirós is probably the nineteenth century Portuguese writer with the most international projection. Mário de Carvalho currently has a vast work of more than thirty years that has been awarded in Portugal and abroad. They have in common the formative and reforming intention through a merciless irony and sharp criticism of their societies. Mário de Carvalho is also an enthusiastic reader of Eça that he often mentions. This article analyzes some aspects and institutions of Portuguese society that deserve their criticism, namely journalism, politics, churches and the dominant culture. The responsibility to move away citizens from their apathy towards culture and politics is evident in these two authors who not only bear witness to Portuguese society, but convey moral indignation against all forms of submission to the established powers.

\section{PALAVRAS-CHAVE:}

Literatura portuguesa contemporânea; crítica social; instituições; ironia.

\section{KEYWORDS}

Modern portuguese

literature;

social critique;

institutions;

irony. 


\section{1.}

É em Mário de Carvalho, indubitavelmente, em conjunto com Rui Zink, que hoje mais se faz sentir a tradição portuguesa do realismo irónico de Eça de Queirós, isto é, uma visão crítica e impiedosa, sanguínea e humorada do estado de Portugal. ${ }^{1}$

Estas palavras, escritas por Miguel Real, transmitem a ideia da legitimidade de aproximação de Mário de Carvalho e Eça de Queirós. Romancistas separados por mais de um século, são frequentemente considerados representantes da literatura portuguesa e é a atenção ao ambiente social que os rodeia que se espelha na crítica acutilante exibida nos seus romances da vida pública em Portugal. O "riso que peleja" 2 , o temperamento crítico e a ironia de Eça, que Campos Matos identifica como reação desesperada ao meio nacional, igualmente se podem identificar em Mário de Carvalho.

Já em Prosas Bárbaras, primeiro publicadas a partir de $1866 \mathrm{em}$ folhetim num jornal da época, a Gazeta de Portugal, encontramos em Eça a crítica da realidade com intenção formadora e reformadora que depois se foi espalhando e diluindo pelos seus romances: "Atenas produziu a escultura, Roma fez o direito, Paris inventou a revolução, a Alemanha achou o misticismo. Lisboa que criou? O Fado."3 O que tem o seu eco na pergunta de Mário de Carvalho: "Há emenda para este país?"4

Entre os dois autores há singulares analogias no que respeita ao modo de interpelar grandes questões sociais, culturais e políticas do seu tempo. Além disso, a amargura latente que contrasta com o tom jocoso das obras denota aquele desespero que pode ter a capacidade de melhor interpelar o leitor e a sociedade. Talvez por isso ambos gozaram de receção favorável na crítica coeva e de projeção internacional, patentes,

\footnotetext{
${ }^{1}$ REAL, Miguel. "O realismo irónico". In: JL - Jornal de Letras Artes e Ideias, no 1032, de 21 de abril a 4 de maio de 2010, p. 13.

2 "Riso que peleja" é uma expressão que Campos Matos retirou da advertência do próprio Eça que consta d'Uma Campanha Alegre. Segundo Matos, este seria o fator determinante para que a obra de Eça tivesse uma maior empatia junto do público brasileiro do que aquela que gozou no seu país. In: MATOS, Campos. (s/d) "Sobre a receção literária de Eça de Queirós". Disponível em: <http://ler.letras.up.pt/uploads/ficheiros/2863.pdf>.

${ }^{3}$ QUEIRÓS, Eça. Prosas bárbaras. Porto: Lello \& Irmãos - Editores, 1945, p. 190.

${ }^{4}$ CARVALHO, Mário. Fantasia para dois coronéis e uma piscina, Lisboa: Caminho, 2003, p. 227.
} 
por exemplo, nas traduções das suas obras para várias línguas e na atenção que tem merecido por parte de estudiosos e de críticos. Eça de Queirós é provavelmente o escritor português do século XIX com mais projeção internacional. Mário de Carvalho possui uma vasta obra de mais de trinta anos que tem merecido a atribuição de vários prémios literários, nacionais e estrangeiros.

O exercício profissional do Direito e o interesse pela política são outros pontos comuns aos dois autores que deixam refletir nos seus textos não só um clima de confronto de valores mas também de questionamento de direitos e deveres que podem motivar o leitor a uma reflexão sobre a ética, a moral e o direito e como se processa, individual ou coletivamente, a escolha e a decisão entre o bem e o mal. ${ }^{5}$

Esta aproximação parece também legitimar-se pelas próprias palavras de Mário de Carvalho que, pontualmente, presta tributo a Eça. Por exemplo, através do narrador (que se autodenomina autor) de $A$ arte de morrer longe, quando ele proclama a sua admiração pelo "grande Eça de Queirós" a propósito da sua denúncia de fenómenos e instituições da vida pública que parecem atravessar o tempo: o jornalismo, a política, as igrejas e a cultura dominante na sociedade portuguesa. A alguns aspetos dessa denúncia iremos agora prestar atenção, iniciando com uma citação de Mário de Carvalho a propósito do jornalismo.

\title{
2. O jornalismo
}

\begin{abstract}
Os leitores mais advertidos hão de lembrar-se de um jornal chamado Corneta do Diabo, escrito por um tal Palma Cavalão, criação do grande Eça de Queirós: ‘Ora viva, Sô Maia!'. Pois bem, os bons espíritos encontram-se, como reza o ditado, e não só se encontram no espaço, mas também no tempo. Quase cento e cinquenta anos depois, os ecos estrídulos da Corneta do Diabo ressoam diariamente na Internet, em piruetas de comentários soezes, chalaças, calúnias, mistificações e ordinarices, sob o mesmo anonimato, e pela verve de Quinta Malpique e seus milhentos confrades. ${ }^{6}$
\end{abstract}

Esta passagem alude a um episódio d'Os Maias de Eça de Queirós, em que um jornalista, Palma Cavalão, aceita publicar por dinheiro um artigo difamatório na Corneta do Diabo, um jornal que dirigia. Ora é a classe jornalística a mais visada em Era bom que trocássemos umas ideias sobre o assunto. Neste romance, facilmente encontramos o reflexo de

\footnotetext{
${ }^{5}$ Para a relação da obra de Mário de Carvalho com o Direito, ver CARVALHO, Dealtina. Propagandistas, vadios e outros manipuladores do direito na obra "Quando o diabo reza" de Mário de Carvalho. Dissertação de mestrado apresentada à Universidade Aberta, 2015. Disponível em: <http://hdl.handle.net/10400.2/5633>.

${ }^{6}$ CARVALHO, Mário. A arte de morrer longe. Lisboa: Caminho, 2010, p. 96.
} 
Palma Cavalão na personagem Eduarda Galvão, uma jovem inculta (não sabia francês, não tinha cultura literária e dava muitos erros ortográficos) que entra no meio jornalístico onde rapidamente ascende por ter descaramento e falta de escrúpulos. Eduarda começa por trabalhar na revista Modelar e, relacionando-se sempre com as chefias, "em apenas dois meses conseguiu grandes vitórias importantes para o ego".7 Rapariga atrevida e com uma natural "técnica de atração" 8 que a faz insinuar-se junto do sexo oposto quando percebe que daí pode tirar proveito, rapidamente se muda para a revista Reflex onde não olha a meios para garantir o seu lugar.

A propósito desta personagem, o narrador comenta ironicamente:

A metamorfose de Eduarda foi tão rápida que eu suspeito de que andou por ali uma fada, que fez trabalhar a varinha competente nesse preciso momento, operando a metamorfose de Eduarda após ter operado a do batráquio. ${ }^{9}$

Para podermos avançar mais e seguindo um paralelismo já apontado por Arnaut 10 , invocamos o incumprimento de regras deontológicas no mundo do jornalismo que une $O$ crime do padre Amaro de Eça e Era bom que trocássemos umas ideias sobre o assunto de Mário de Carvalho.

$\mathrm{O}$ redator do jornal Voz do Distrito instiga a escrita de artigos difamatórios anónimos e de denúncia da igreja sem qualquer preocupação acerca da veracidade dos factos: " - Havendo escândalo, conta-se! Não havendo, inventa-se!"11 posição que altera consoante os seus interesses pessoais se vão alterando também. De igual modo, a jornalista Eduarda Galvão é alheia a qualquer sentido ético no exercício da sua profissão. Numa entrevista a Agustina Bessa Luís, não é capaz de anotar convenientemente as palavras da escritora e então recorre a um antigo professor, Jorge Matos, para as reconstituir o qual, sem sucesso, procura incutir-lhe princípios deontológicos que deveriam ser intrínsecos a qualquer jornalista:

A entrevista com Agustina lá foi redigida, sem que a própria
fosse, para o efeito, vista nem achada, descontando os retalhos
da conversa que tinha tido com jornalistas pela vida fora e que
Jorge desencantara, dando-lhes, em parte, uma volta. Tentou
explicar a Eduarda que aquilo era uma autêntica fraude, mas

7 CARVALHO, Mário. Era bom que trocássemos umas ideias sobre o assunto. Porto: Coleção mil folhas /Ed. Público, 2002 [1995], p. 58.

${ }^{8}$ Idem, ibidem, p. 61.

${ }^{9} I d ., i b ., i b$.

${ }^{10}$ ARNAUT, Ana Paula. Post-Modernismo no Romance Português Contemporâneo - Fios de Ariadne - Máscaras de Proteu. Coimbra: Almedina, 2002.

${ }^{11}$ QUEIRÓS, Eça. O crime do padre Amaro. Barcarena: Editorial Presença, 2005 [1875], p. 136. 
ela mostrou-se pouco sensível ao vocábulo e ainda menos ao conceito. ${ }^{12}$

A falta de cultura literária destes profissionais - outro dos aspetos visados - é reiterada na personagem Bernardo Veloso, o próprio editor da Reflex:

Bernardo Veloso tinha lido três livros na vida, o que, considerando a média de leituras de alguns seus iguais, deve ser considerado uma vantagem comparativa invejável. Eram eles $O$ Senhor dos Anéis de Tolkien, $O$ Rinoceronte de Ionesco e $O$ Falcão de Malta de Dashiell Hammett e, pode garantir-se, nunca houve livros mais bem lidos em todo o mundo."13

Podemos concluir, com Carlos Reis, que, relativamente aos jornalistas, a obra de Mário de Carvalho deixa transparecer:

a perversa instalação, nalguma imprensa de vasta circulação, do comentário jornalístico de circunstância, sem profundidade crítica nem cultura literária, comentário capaz de enunciar banalidades depreciativas, provindas de quem mal folheou um livro e menos ainda conhece a obra do autor, o género em que (eventualmente) escreve ou as interações temáticas que atravessam o texto. ${ }^{14}$

\section{A política}

Da leitura de As Farpas, se pode concluir que Eça de Queirós não via ideias em Portugal, apenas etiqueta. N'Os Maias, o conde de Gouvarinho é um político ignorante e de horizontes limitados, tal como outra personagem, Sousa Neto, funcionário ligado à educação pública. Durante um jantar, este revela não perceber nada sobre o socialismo utópico de Proudhon, uma referência cultural importante na época, e isso impede o decorrer normal da conversa:

- Vossa Excelência, decerto, Sr. Sousa Neto, conhece perfeitamente o seu Proudhon? (...) - Não sabia - disse ele com um sorriso infinitamente superior - que esse filósofo tivesse escrito sobre assuntos escabrosos!"15

\footnotetext{
${ }^{12}$ CARVALHO, 2002, p. 177.

${ }^{13}$ Idem, ibidem, pp. 84-5.

${ }^{14}$ REIS, Carlos. "Mário de Carvalho: Incitação ao romance". In: Jornal de Letras, ano XVI, n 675, 28 de agosto, 1996, p. 22.

${ }^{15}$ QUEIRÓS, Eça. Os Maias. In:

<http://figaro.fis.uc.pt/queiros/obras/Maias/Maias_20001210.pdf, p. 286>.
} 
Mas é n'O Conde d'Abranhos, obra póstuma publicada em 1925, que a classe política é especialmente visada. Aí Eça faz uma crítica feroz à política institucional através da biografia de Alípio Abranhos num registo irónico. O seu percurso é-nos contado através do discurso do secretário do conde que, pretendendo fazer o enaltecimento do estadista, o desmascara a cada frase aparentemente elogiosa. Abranhos ascendeu na carreira por hábeis contactos até ser nomeado Ministro da Marinha sem perceber nada da marinha, tendo ficado célebre com a tirada na Câmara dos Deputados sobre Moçambique que referiu ficar a ocidente de África. Abranhos representa todo o Ministério das colónias que Eça aponta a dedo através dos políticos deste ministério que nelas viam apenas "o estrangeiro que as explora". Num Portugal ainda monárquico, era a favor da democracia, pois não via a necessidade de se combater a plebe quando é fácil iludi-la, amolecendo-a na indiferença e exercendo a soberania em proveito próprio:

os governos democráticos conseguem tudo, com mais segurança própria e toda a admiração da plebe, curvando a espinha e dizendo com doçura: - Por aqui se fazem favor! Acreditem que é o bom caminho!.16

Mais de um século passado, é esta indiferença que é pano de fundo na história de uma burla que é contada em Quando o Diabo reza, de Mário de Carvalho, que teve a primeira edição em 2011. Enquanto as personagens principais, que são "dois vadios e uma galdéria", preparam esquemas tortuosos e ilícitos, movem-se personagens anónimas em campanha eleitoral obscura, pois não se sabe para que fins ela decorre, que vai interrompendo a ação sem a influenciar de algum modo e sem interessar ninguém:

Bartlo saia tão compenetrado de casa de Cíntia que passou pelo meio duma arruada de campanha eleitoral quase sem dar por isso. Uma mocinha saltitante, com uma T-shirt cheia de dizeres, intercetou-o e estendeu-lhe um papel todo colorido. Bartlo, rosnando:

- Vai fritar moscas!17

Após quinze dias de "ruído e escarcéu"18 com distribuição de artefactos inúteis, bandeiras e panfletos, laconicamente vem o desfecho que mostra a irrelevância do ato para a vida individual e para a sociedade: "Houve eleições. Uns ganharam, outros perderam". 19

\footnotetext{
${ }^{16}$ QUEIRÓS, Eça. O conde d' Abranhos. Porto: Lello \& Irmãos Editores, 1981 [1925], p. 40.

17 CARVALHO, Mário. "Quando o diabo reza". In: Crononovelemas. Lisboa: Porto Editora, 2017 [2011], p. 183.

${ }^{18}$ Idem, ibidem, p. 169.

${ }^{19} I d .$, ib., p. 249.
} 
O Conde d'Abranhos parece ter o seu correlato em Rui Alves, personagem do romance de Mário de Carvalho de Era bom que trocássemos umas ideias sobre o assunto. Rui Alves é um homem medíocre, com uma licenciatura em Antropologia Analítica, obtida na Suíça, por ser incapaz de a fazer em Portugal, pois "dava muitos erros de ortografia". ${ }^{20}$ Ora é este homem que, ironicamente, está no topo da hierarquia duma importante instituição promotora de ações culturais em Lisboa.

A ignorância pelos políticos de hoje sobre as situações reais parece ser uma continuação da ignorância do conde. Em $A$ arte de morrer longe, o narrador ridiculariza a norma legal que obriga os proprietários a eliminar a vegetação cinquenta metros em redor das casas e que "vai necessariamente provocar uma absoluta desertificação a norte do Guadiana". ${ }^{21}$ A citação é longa mas vale a pena na sua ironia demolidora:

Na verdade, o nosso legislador é abstrato e geral, tão abstrato e geral que se desinteressa do que sejam dez metros, dezassete metros, quanto mais cinquenta metros. Deve ter considerado desprimoroso dar-se ao trabalho de comprar uma fita métrica, dessas extensíveis que há no mercado e medir a distância no terreno. Depois desta operação simples, não seria demais sugerir que meramente circunvagasse o olhar e considerasse os resultados duma desflorestação.

Esta repugnância comichosa do legislador pelos números não é novidade. Em 1974 considerou que o direito de manifestação podia ser impedido a menos de cem metros de determinados edifícios o que tornaria praticamente impossíveis os protestos coletivos em qualquer município a começar por Lisboa. Compreende-se que para homens públicos cansados, depois de noites insones, em que um propunha quatro metros, outro, nenhum metro e outro, quinhentos metros, se tenha obtido uma solução que fazia a média das propostas apresentadas à mesa. Tratava-se de mostrar força, de ganhar ou perder, sem importar exatamente o quê. Se fosse uma questão de rebanhos de gabirus, ou reservas de índios, ou ilhas de coral, também se discutiriam os números até altas horas da noite, até se votar uma solução satisfatória. (...) Imagino um governante a chegar a casa, a dizer ao mordomo (publicamente apresentado como 'um primo da província, coitado, que vive cá em casa'): 'Andrade, passe-me aí um uísque velho com soda que tenho de comemorar uma coisa.' E para a mulher, que acorria em roupão: 'Imagine, Maria de Santa Clara, que conseguimos regulamentar o direito de manifestação à semelhança do mundo civilizado. Não me felicita?' E, depois, 'Olhe, o que é exatamente um metro?22

${ }^{20}$ CARVALHO, 2002, p. 17.

${ }^{21}$ CARVALHO, Mário. A arte de morrer longe. Lisboa: Caminho, 2010, p. 35.

${ }^{22}$ Idem, ibidem, pp. 36-7. 
E de novo a homenagem a Eça, na rememoração do seu criado Vitorino, "a quem dava tanto um livro de Química como uma peça de teatro, 'porque eram tudo coisas em letra redonda'". ${ }^{23}$

\title{
4. As igrejas
}

A obra de Eça de Queirós patenteia o pensamento anticlerical que atravessou parte do século XIX e que se relacionava, não tanto com o ideal cristão, mas sim com o peso institucional da igreja, então exclusivamente católica, na vida pública e nos lares burgueses. O Crime do Padre Amaro é o romance que incide precisamente nesta questão. A proximidade da jovem Amélia com o cónego Dias, presença tão frequente na sua casa que este se considerava membro da família, as intimidades dele com a sua mãe, criam o meio para que sinta atração pelo atraente padre Amaro, recém-chegado à cidade e à sua casa. Numa cena do romance que descreve um jantar de clérigos, cada um relata experiências diversas para obter favores e dinheiro para a sua paróquia. Por exemplo, o padre Natário conta como usa a confissão para arrecadar alguns fundos: "O que eu quero dizer é que é um meio de persuasão, de saber o que se passa, de dirigir o rebanho aqui ou para ali...e quando é para o serviço de Deus é uma arma..." 24

No Portugal de hoje em que o culto católico se insere no pluralismo que a liberdade religiosa consagra, algumas das seitas e igrejas estão perigosamente coladas à marginalidade e são disfarce para muitas atividades ilícitas.

Bartlo, um dos dois vadios de Quando o diabo reza, consegue revestir-se de uma aparência séria e distinta e aceita participar ativamente nas atividades da congregação:

\begin{abstract}
Bartlo, seguindo o conselho da mãe, arranjara rapidamente um lugar de 'coadjuvante' na igreja, superior a 'prestes' e a 'fâmulo'. Assistia ao tabernáculo, muito sério, cheio de peneiras, com o Hugo Boss a resplandecer. Dotado daquela palheta, não tardaria a ser promovido a "caduceu" de terceira, com direito a dirigir-se aos fiéis, em breves exortações. A mãe dizia às vizinhas que o rapaz tinha encontrado a 'via' e que estava cheia de orgulho. ${ }^{25}$
\end{abstract}

Também Manfredo Tendeiro, outra personagem do mesmo romance, é frequentador da mesma igreja da qual se serve para iludir uma

\footnotetext{
${ }^{23}$ CARVALHO, 2010, pp. 36-7.

${ }^{24}$ QUEIRÓS, 2005, p. 98.

${ }^{25}$ CARVALHO, 2017, pp. 252-3.
} 
aparência de dignidade patriarcal, escolhendo sempre um lugar de honra. Manfredo Tendeiro está envolvido em negócios de contrafação e falsificação de roupa de grandes marcas, fornecendo-a para os delinquentes passarem por doutores e empresários em golpes de vária natureza. A par da sua banca de roupa nas feiras, está envolvido em atividades criminosas de variadíssima natureza que implicam gente do jet set,

atividades que tinham por trás gente importante, da mais reputada que havia na Península, alguma sempre a dar ao serrote e a mostrar a dentadura nas revistas forradoras de quiosques. Tratava-se de operações abrangidas pela designação genérica de 'limpeza e desbaste', que obrigavam a um trabalho coletivo, coordenado, diversificado e persistente. ${ }^{26}$

A "limpeza e desbaste" podia consistir em tornar a vida insuportável a inquilinos com rendas baixas ou mesmo a atear fogo aos edifícios em que viviam.

A Igreja Irmãos em Cristo, que alberga estes delinquentes, propagandeia uma igualdade que é apenas aparente. Aceita a pobreza, desde que cada um pague a sua parte do dízimo. O misto de retórica, prosápia, salvação espiritual e negócios ilícitos que as novas igrejas instituídas acolhem propicia novas divisões e parece adaptar-se a todos os gostos e todas as circunstâncias de vida: “- Mas, ó mãe, não há milionários nesta igreja. Esta é especializada em pobres. Os ricos vão para a outra". ${ }^{27}$ A prodigalidade de lugares-comuns compostos por oposições simples tais como "treva e luz", "deboche, pureza", "deserto, jardim", parece, no entanto, ter bom acolhimento nos ouvintes:

O oficiante "tinha um discurso ligado, palavra a palavra, e o tom ia crescendo à medida que a noite se adiantava. Olhares embalados, ouvidos confortados, almas arrebatadas. [...] Via-se mesmo que havia algo de superior e iluminado a falar pela boca dele. Toda a gente estava de acordo. Diziam "iá!", abanavam as cabeças e repetiam 'Áleluia' ${ }^{28}$

Também o bispo de Grudemil, em Era bom que trocássemos umas ideias sobre o assunto, é retratado com atributos contrários à prática do sacerdócio. Por exemplo, revela um gosto sádico em torturar os animais nas caçadas "perfurando-os, rebentando-lhes as cabeças, fazendo-lhes saltar os olhos, pendentes das órbitas por filamentos enlameados e, finalmente, pendurando-os à cintura, ainda frémitos de dores, a esvair-se

\footnotetext{
${ }^{26}$ A ortografia foi modificada do original segundo o acordo ortográfico. In: CARVALHO. Id., ib.

${ }^{27}$ Idem, ibidem, p. 197.

${ }^{28} I d$., ib., p. 156.
} 
em sangue" .29 $\mathrm{O}$ narrador, logo de seguida, de forma jocosa, conta-nos o "castigo terreal" por tão escabrosos atos. O bispo foi alvo de interesse dos jornalistas pelo facto de ter mordido um cão, notícia que suscitou grande curiosidade em todo o mundo. ${ }^{30}$

N'O conde Jano (1991), é evidente a duplicidade social e moral do frade conselheiro que legitima um crime e o abuso de poder. ${ }^{31}$ Numa ação situada num tempo remoto, a filha do rei tinha exigido a morte de uma condessa e o rei procura corresponder a essa imposição, mas ao mesmo tempo salvar as aparências através do frade que lhe fornece o argumento para tal:

- A felicidade dos príncipes, meu rei, tem boa conta na felicidade dos povos que é a razão de ser do múnus que Deus lhes confiou e em Seu nome exercem.

Sendo caso, valerá sacrificar uma vida para alcançar a felicidade da infanta, pois assim se pouparão muitas outras que sucumbiriam à infelicidade dela, que seria sempre má conselheira de imponderações e de injustiças. ${ }^{32}$

A instrumentalização da igreja para fins políticos, que alguns sociólogos veem como instrumentalização mútua, embora possa ser típica de governos autoritários que assim buscam na igreja uma instância de legitimação, é um fenómeno que atravessa o tempo e o espaço. ${ }^{33}$ Mas o que ressalta em Quando o Diabo reza é que as igrejas servem de cobrimento a negócios ilícitos a nível individual.

\section{A cultura dominante}

Talvez seja Eça, como nenhum outro escritor do século XIX, aquele que desvenda a importância da ópera de S. Carlos enquanto lugar de convívio social equivalente ao passeio público em vez de ponto cultural

\footnotetext{
${ }^{29}$ CARVALHO, 2002, p. 110.

${ }^{30} \mathrm{Idem}$, ibidem, p. 112.

${ }^{31}$ Para a análise deste conto ver SEQUEIRA, Rosa Maria. "O Conde Jano de Mário de Carvalho: uma história de desejo no desejo de história" - Atas do Colóquio Literatura e História, realizado na Universidade Aberta em outubro de 2002. Lisboa: Universidade Aberta, 2005, pp. 285-296 (CD-ROM). In:

<https://repositorioaberto.uab.pt/bitstream/10400.2/320/1/ACTAS-

LiterAtura \%20e\%20Hist\%c3\%b3ria285-296.pdf.pdf>.

${ }^{32}$ CARVALHO, Mário. Quatrocentos Mil Sestércios seguido de O Conde Jano (novelas). Lisboa: Caminho, 1991, p. 102.

${ }^{3}$ Ver, a propósito, OLIVEIRA, Fabrício. "Religião e participação política. Considerações sobre um pequeno município brasileiro", e-cadernos, 13, 2011. In:

<https://journals.openedition.org/eces/568> ou SANTOS, Paula. A política religiosa do Estado Novo (1933-1974): Estado, leis, governação e interesses religiosos. Tese de doutoramento apresentada à Universidade Nova de Lisboa, 2012. In:

<https://run.unl.pt/bitstream/10362/8617/1/PBS_Tese.pdf>.
} 
num modelo de comunicação que, como refere Vieira de Carvalho, consistia sobretudo na exposição do eu. ${ }^{34}$

A seguinte cena d'Os Maias, passada no Teatro da Trindade durante um sarau, dá a medida da cultura da época através da perspetiva crítica do narrador:

No entanto, por toda a sala, o sussurro crescia. Os encatarroados tossiam livremente. Dois cavalheiros tinham aberto A Tarde. E caído sobre o teclado, com a gola da casaca fugida para a nuca, o pobre Cruges, suando, estonteado por aquela desatenção rumorosa, atabalhoava as notas, numa debandada. Fiasco completo. 35

A peça musical a que o público, composto por altos burgueses e aristocratas, reagiu com tal incivilidade era a sonata Patética de Beethoven. Eça conhecia bem a cultura europeia, daí se referir com desgosto ao estado musical do Portugal da época:

E quanto à música, refugiou-se nos cafés-concertos, nos realejos e nas harpas da rua; refugiou-se também nos pianos das meninas. Todo o mundo acha adoráveis as músicas dos pianos particulares; também acho bom, mas prefiro a forca. ${ }^{36}$

E se Vieira de Carvalho refere a crítica de Eça ao sistema da sociedade liberal ${ }^{37}$ os romances de Mário de Carvalho deixam transparecer o mesmo. Os vários narradores dos seus romances não hesitam em apontar nomes reais conhecidos do público português da cultura popular e de massas, por exemplo, o "senhor Toy" e o "senhor Marco Paulo". O disco de platina de Soraia Marina possui letras deste género: "Meu amor não respondeste/ quando te vi junto ao mar/ Tu então não me quiseste/ Deixa-me vai-te matar". ${ }^{38}$ Nestas canções, "a

\footnotetext{
${ }^{34}$ CARVALHO, Mário Vieira de. "Eça de Queirós e a ópera no século XIX em Portugal", Colóquio Letras, 91, 1986, p. 25. Vieira de Carvalho demonstra como, a partir dos romances de Eça, a ópera participava de um processo de alienação. In:

$<$ http://coloquio.gulbenkian.pt/bib/sirius.exe/issueContentDisplay? $\mathrm{n}=91 \& \mathrm{p}=27 \& \mathrm{o}=\mathrm{r}>$.

Para o estudo dos aspetos musicais na obra de Eça, ver PINTO, Paul; PINTO, Judith. "Music as Narrative in Eça de Queirós' O Primo Basílio". In: Hispania 73.1 (March 1990): 50-65; CARVALHO, Mário Vieira de. Eça de Queirós e Offenbach: a ácida gargalhada de Mefistófeles. Lisboa: Edições Colibri /Faculdade de Ciências Sociais e Humanas da Universidade Nova de Lisboa, 1999 e FERRO, Luís dos Santos. "Música". In: CAMPOS MATOS (org. e coord.). Dicionário de Eça de Queiroz, 2a ed. rev. e aumentada. Lisboa: Caminho, 1993, pp. 633-644.

${ }^{35}$ QUEIRÓS, Eça de. Os Maias, p. 431.

${ }^{36}$ Correspondência de $O$ Distrito de Évora, no. 3, 13 de janeiro de 1887. In: QUEIROZ, Eça de. Prosas Esquecidas, II, p. 306.

${ }^{37}$ CARVALHO, Mário Vieira de. Eça de Queirós e Offenbach: a ácida gargalhada de Mefistófeles. Lisboa: Edições Colibri /Faculdade de Ciências Sociais e Humanas da Universidade Nova de Lisboa, 1999, p. 31.

${ }^{38}$ CARVALHO, 2003, p. 126.
} 
música era quase tão boa como a letra" ${ }^{39} \mathrm{O}$ humorista Ricardo Araújo Pereira (2007) também se pronuncia sobre a letra das canções de outro cantor popular, Tony Carreira. Comenta ele os dois seguintes versos, "Vem para mim bamboleando/ escorrega nos meus lábios": "este último parece alertar para o caráter traiçoeiro dos beijos, que ora fazem tropeçar ora saem de lábios escorregadios. A registar, por quem, desejando entregar-se aos prazeres do amor, não queira, ainda assim, partir uma perna". ${ }^{40}$ Mais uma vez se repete o fenómeno retratado n'Os Maias: a música predominante na sociedade portuguesa é a sua caricatura.

Todos estes cantores populares, sendo praticamente inexistentes enquanto atuam em feiras e romarias, podem ser rapidamente promovidos através da televisão cuja programação é grandemente dedicada a este tipo de música, a concursos bizarros e a telenovelas que personagens de educação superior consomem. Em $A$ arte de morrer longe, presenciamos o que fazem as personagens Arnaldo e Bárbara ao serão:

\begin{abstract}
"Assistiam a uma daquelas intermináveis peças narrativas que as televisões exibem por volta da hora do jantar e que dão pelo nome de telenovelas, folhetins televisivos que parecem destinados de propósito e muito sabiamente às pessoas que deixam divagar o espírito para longe do clarão em que os olhos estão postos, como acontece aos casais desavindos e já pouco firmados na desavença. As situações e próprias as falas são habilidosamente repetidas, de maneira que, por mais distraído que se esteja, há grande improbabilidade de se perder o fio da história". ${ }^{41}$
\end{abstract}

Em Era bom que trocássemos umas ideias sobre o assunto é ridicularizada a programação televisiva que não anda longe da realidade no tipo de concursos, reality shows, filmes e documentários que oferece. Por exemplo, "um concurso em que um fulano tomava banho num composto espesso de banha de porco e dejetos de pardal e depois se lambia, com acompanhamento de morangos e felicitações dum vasto público" 42; "um programa em que um marinheiro regressava após vinte anos de ausência, com uma perna a menos devido à dentada dum tubarão e a mulher, recebendo-o de braços abertos, bradava: 'Assim ainda gosto mais de ti, caraças!'"43; "um filme em que o herói derrubava um bandido, lhe traçava as costas com cinco ou seis facadas horizontais, lhe sacava as costelas para fora e as partia, uma a uma com estalidos

\footnotetext{
${ }^{39}$ Idem, ibidem, p. 126.

${ }^{40}$ PEREIRA, Ricardo Araújo. Boca do inferno. Lisboa: Tinta-da-China, 2007, p. 13.

${ }^{41}$ CARVALHO, 2010, pp. 98-9.

${ }^{42}$ CARVALHO, 2002, p. 29.

${ }^{43} \mathrm{Idem}$, ibidem, ibidem.
} 
fortes e repulsão de matérias rubras"44; e, finalmente, um documentário que explora o sentido de orientação da mosca drosófila.

O gosto literário predominante pertence ao mesmo registo da ausência de critérios e de escrita. Os best sellers da época de Eça que eram a apoteose do adultério, segundo as suas palavras n'As Farpas ${ }^{45}$, e sobre os quais as mulheres derramavam lágrimas de sensibilidade, têm no presente o seu equivalente nos adocicado[s] livro[s] do senhor Paulo Coelho. ${ }^{46}$

\section{Conclusão}

A ação nos romances de Eça e de Mário de Carvalho permite o reconhecimento duma cidade cosmopolita nos hábitos duma população heterogénea que se apresenta em discurso direto sob diferentes grupos económicos, culturais e profissionais e age de acordo com a sua pertença a cada um deles. Os respetivos autores /narradores descrevem as ações, as introspecções, as relações de convivência, formas de vida e de socialização, integrando as suas personagens em grupos familiares, religiosos, profissionais, sociais e políticos, caracterizados com uma linguagem e sonhos identificáveis quer no Portugal dos anos 1800 quer dos últimos anos. Esta verosimilhança agita o leitor, provocando-lhe o riso e interpelando-o para o que está mal e precisa de ser reformado seja a "ferrugem nacional", referida por Eça, seja uma "realidade muito abusadora", expressão que o narrador de Era bom que trocássemos umas ideias sobre o assunto não se cansa de repetir. ${ }^{47}$ Em Eça, são especialmente visados os representantes das classes dirigentes do Portugal da Regeneração. As personagens são marcadas por aquilo que a crítica eciana chama representatividade social. Já em Mário de Carvalho há uma atenção à nova composição social heterogênea do Portugal do século XXI e a fenómenos recentes num clima de manipulação de valores e de confronto de poderes e interesses, em que as personagens estão em conflito consigo próprias e com as instituições. Ressalvada esta diferença contextual basilar, quase todas as personagens carvalheanas espelham a conformação perante um estado de coisas em tagarelice vazia, em aturdimento, mero "falatório", "falajar" ou "zunzunar" sem sentido48 que se espalha pelo país, abrangendo todas as profissões e classes sociais e que parece ser um reflexo das campanhas eleitorais:

\footnotetext{
${ }^{44} I d ., i b ., i b$.

${ }^{45}$ QUEIRÓS, Eça e ORTIGÃO, Ramalho. “As Farpas". 2004 [1882] In:

$<$ https:// sanderley.com/PDF/Eca-de-Queiros/Eca-de-Queiros-As-Farpas-Junho-a-Julho1882.pdf>.

${ }^{46}$ CARVALHO, 2003, p. 33.

${ }^{47}$ CARVALHO, 2002, pp. 164, 198 e 213.

${ }^{48}$ CARVALHO, Mário. Fantasia para dois coronéis e uma piscina. Lisboa: Caminho, 2003, p. 11.
} 
O país fala, fala, desunha-se a falar, e pouco do que diz tem o menor interesse. $\mathrm{O}$ país não tem nada a dizer, a ensinar, a comunicar, $\mathrm{O}$ país quer é aturdir-se. E a tagarelice é o meio de aturdimento mais à mão. ${ }^{49}$

A responsabilidade de trazer os cidadãos da apatia em que estão quanto à cultura e à política é evidente em Eça e Mário de Carvalho que não apenas dão um testemunho da sociedade portuguesa em que viveram, mas transmitem a indignação moral contra todas as formas de submissão aos poderes ou aos mercados de que falava Bourdieu, uma outra forma de tomar consciência da correlação entre estruturas objetivas e habitus incorporados. ${ }^{50}$ Todos os grandes romances são obras antropossociológicas de riqueza cognitiva e visionária, diz-nos, por seu turno, Edgar Morin. 51

Por isso o realismo quotidiano não pode deixar de estar ligado a elementos éticos que são inerentes a essa sentida responsabilidade e fazem parte da representação do desencanto perante a vida pública. Os dois autores são atraídos pela contemporaneidade decadente numa representação realista composta por um pano de fundo social e por sentimentos e valores individuais donde não é possível eliminar a ética. A obra de Eça abalava o público lisboeta do tempo, tal como os romances de Mário de Carvalho abalam o leitor de hoje, proporcionando-lhe uma compreensão do mundo e obrigando-o a reposicionar-se perante a possibilidade de uma alternativa. A consciência estética tem assim uma força subversiva.

Rosa Maria Sequeira é professora no Departamento de Humanidades na Universidade Aberta e investigadora integrada no CEMRI - Centro de Estudos das Migrações e das Relações Interculturais, centro que coordenou entre 2013 e 2016. Tem-se dedicado, no ensino e na investigação, à Comunicação Intercultural e aos Estudos Comparados. É autora de Desejo e sedução. A circulação intercultural do donjuanismo, Lisboa: UAb /CEMRI /FCT, 2017. Contato: rosa.sequeira@uab.pt

Maria Cecília Vieira leciona Português e Literatura Portuguesa numa escola secundária. É licenciada em Línguas e Literaturas Modernas, mestre em Estudos Portugueses Multidisciplinares e doutorada em Literatura Portuguesa. É investigadora integrada no CEMRI - Centro de Estudos das Migrações e das Relações Interculturais da Universidade Aberta no Grupo de Investigação de Comunicação Intercultural. A sua investigação de doutoramento versou sobre a obra de Mário de Carvalho no contexto do pós-modernismo. Contato: ceciliasousavieira@hotmail.com

${ }^{49}$ CARVALHO, 2003, p. 11.

${ }^{50}$ BOURDIEU, Pierre. Razões Práticas: sobre a teoria da ação, tradução de Mariza Corrêa.

Campinas: Papirus Editora, 2008 [1994].

51 MORIN, Edgar. L'esthétique et l'art du point de vue d’une anthropologie complexe. Lisboa: Gulbenkian, 2016. 